\title{
The role of adrenomedullin in the pathogenesis of gastric cancer
}

\author{
Fuhao Qiao ${ }^{1,2}$, Jian Fang ${ }^{1}$, Jinfeng $\mathrm{Xu}^{1}{ }^{1}$, Wenqiu Zhao ${ }^{1}$, Ying $\mathrm{Ni}^{1}$, Bufugdi Andreas \\ Akuo $^{1}$, Wei Zhang ${ }^{1}$, Yun Liu ${ }^{1}$, Fangfang Ding ${ }^{1}$, Guanlin Li ${ }^{3}$, Baoguo Liu ${ }^{4}$, Hua Wang ${ }^{1}$ \\ and Shihe Shao ${ }^{1}$ \\ ${ }^{1}$ School of Medicine, Jiangsu University, Zhenjiang 212013, Jiangsu, PR China \\ ${ }^{2}$ Medical Laboratory, Xintai Hospital of Traditional Chinese Medicine, Xintai 271200, Shandong, PR China \\ ${ }^{3}$ School of The Environment and Safety Engineering, Jiangsu University, Zhenjiang 212013, Jiangsu, PR China \\ ${ }^{4}$ Nuclear Medicine Laboratory, Taian Jiangong Hospital, Taian 271001, Shandong, PR China \\ Correspondence to: Hua Wang, email: wangjiahan1979@163.com \\ Shihe Shao, email: shaoshihe2006@163.com \\ Keywords: adrenomedullin, autophagy, gastric cancer, RNA interference, signaling pathway \\ Received: August 27, $2016 \quad$ Accepted: June 13, $2017 \quad$ Published: June 29, 2017 \\ Copyright: Qiao et al. This is an open-access article distributed under the terms of the Creative Commons Attribution License \\ 3.0 (CC BY 3.0), which permits unrestricted use, distribution, and reproduction in any medium, provided the original author and \\ source are credited.
}

\section{ABSTRACT}

Adrenomedullin has been shown to be overexpressed in many tumors, including gastric cancer tumors; however, its mechanism of action remains unclear. In this study, we examined the role of adrenomedullin in the pathogenesis of gastric cancer. Using clinical specimens and immunohistochemistry, we found that the expression levels of adrenomedullin and its receptors are inordinately elevated as compared to the adjacent non-tumor gastric tissues. We used siRNA gene silencing, in BGC-823 gastric cancer cell lines, to target adrenomedullin genes, and found that increased adrenomedullin expression results in the proliferation of tumor cells, tumor invasion, and metastasis. Furthermore, we found that under hypoxic conditions, gastric cancer BGC-823 cells exhibit higher expression levels of adrenomedullin and various other related proteins. Our results indicate the involvement of adrenomedullin in microvessel proliferation and partially in the release of hypoxia in solid tumors. Knockdown of adrenomedullin expression, at the protein level, reduced the levels of phosphoprotein kinase B and B-cell lymphoma 2 but increased the levels of cleaved-caspase 3 and Bcl 2 associated $x$ protein (Bax). Therefore, we hypothesized siRNA targeting of adrenomedullin genes inhibits various serine/threonine kinases via a signaling pathway that induces cell apoptosis. SiRNA targeting of adrenomedullin genes and green fluorescent control vectors were used to transfect BGC-823 cells, and western blot analyses were used to detect changes in the rates of autophagy in related proteins using confocal laser scanning microscopy. No significant changes were detected. Therefore, the knockdown of adrenomedullin and its receptors may represent a novel treatment strategy for gastric cancer.

\section{INTRODUCTION}

Andrenomedullin (AM) is a ubiquitous peptide, expressed throughout the body, that can cause pheochromocytoma [1]. Gastric carcinoma is the most common type of malignant cancer after lung and liver cancer, and it is the third leading cause of cancer death worldwide $[2,3]$. Nearly $40 \%$ of patients present with metastatic disease, and approximately $50 \%$ present with loco-regional diseases [4]. Recurrence rates are high, and the five-year survival rate, for all stages, is low, ranging from $25 \%$ to $30 \%$ [4-7]. Despite advances in diagnostic and treatment options, the prognosis of gastric cancer has not improved over the last two decades [8,9]. Many 
studies have shown that the level of AM is significantly elevated in various cancerous tumors, including osteosarcomas [10], pancreatic adenocarcinomas [11], and plexiform neurofibromas [12]. AM, a hormone that regulates stem cell differentiation, also regulates many normal activities in the stomach [13]. AM also plays a role in gastric mucosal defense and repair [14, 15]. In endometrial cancer tissues and chromophobe renal carcinomas, AM mRNA levels have been shown to be elevated, whereas protein expression levels were attenuated $[16,17]$, indicating a putative, complex posttranscriptional regulatory network. In this study, we examined the role of AM in gastric cancer, and analyzed its localization and relationship to the pathogenesis of gastric cancer in clinical samples.

Previous studies have demonstrated that AM plays a pivotal role in several important signaling pathways, including the cAMP, phosphatidylinositol 3-kinase/ Akt-dependent, and ERK signaling pathways. AM, via the phosphatidylinositol 3-kinase/Akt-dependent pathway, induces endothelium-dependent vasorelaxation [18], and infusion attenuates myocardial ischemia/ reperfusion injury [19]. Furthermore, AM signaling, via the activation of the MAPK/ERK pathway, regulates additional downstream signaling pathways that promote endothelial cell growth and survival [20]. AM upregulation of $\mathrm{Bcl}-2$, in an autocrine/paracrine manner, also protects malignant cells from hypoxia-induced cell death [21]. Therefore, AM may have a functional in gastric cancer pathogenesis via the activation of a similar signaling pathway in BGC-823 cells transfected with AM siRNA.

Previous studies have shown when tumor cells were exposed to hypoxic conditions, HIF-1 1 regulated the expression of some genes to aid in the survival of tumor cells [16]. Furthermore, hypoxia-induced expression of AM has been shown to be increased in a variety of tumor cell lines, including multiple myelomas [17], and bladder urothelial cell carcinomas [22]. However, the role of AM under hypoxic conditions has not been described in gastric cancer tumors. Thus, BGC823 cells were cultured under hypoxic conditions to determine whether they respond via the same hypoxiainduced mechanisms.

Autophagy is an evolutionary conserved catabolic process by which cells degrade and are recycled to maintain cellular homeostasis [23]. Autophagy accompanies apoptosis, via ER-stress mediated mechanisms, in human gastric cancer SNU-16 cells [24]. Several reports have demonstrated an alteration in autophagy by the calcium signalosome in human diseases [23]. Furthermore, it has been shown that AM induces $\mathrm{Ca}^{2+}$ mobilization, independent of cAMP levels [25]. Here, we utilize a pcDNA-GFP-LC3 single fluorescent autophagy indicator system to determine the relationship between AM and autophagy.

\section{RESULTS}

\section{$A M$ and $A M$ receptors are highly expressed in gastric adenocarcinomas}

Our results indicate, that in $65 \%$ of the gastric cancer samples examined, AM protein levels were elevated as compared to the adjacent, non-tumor gastric tissues (Figure 1A). Furthermore, the levels of the AM receptors RAMP1, RAMP2, RAMP3, and CRLR were also elevated as compared to their adjacent nontumor gastric tissues by $60 \%, 61 \%, 58 \%$, and $62 \%$, respectively (Figure 1B-1E). The AM mRNA expression levels were analyzed in 35 gastric carcinoma specimens (Figure 2A), and of these 35 specimens, 24 exhibited higher expression levels, representing $68 \%$ of the total specimens examined. A comparative survival analysis of the 60 patients is shown in Figure 2E. Our results show that the expression levels of AM, CRLR, RAMP1, RAMP2, and RAMP3 are higher in gastric cancer tissues than in the adjacent non-tumor gastric tissues, and the patients with the lower expression levels of AM lived longer $(p=0.0258)$. Table 1 illustrates the relationship between AM expression and the clinicopathological factors of the 60 patients. Compared to the gastric cancer samples with low expression ( $0 \%$ to $25 \%)$, those with high expression ( $75 \%$ to $100 \%)$ were found to have larger tumor size $(\mathrm{P}=0.008)$, higher tumor grade $(\mathrm{P}=0.012)$, and higher TNM stage $(\mathrm{P}=0.011)$.

\section{Gene silencing in BGC-823 cells using AM- siRNA}

We selected the highest AM expressing specimens from the four different gastric cancer cell lines examined. Gastric cancer cell proteins were extracted from each of the cell lines, and western blot analyses were used to determine AM expression in the BGC823 cell line (Figure 2C, 2D). qRT-PCR was used to determine the highest expression levels of mRNA in the BGC-823 specimens (Figure 2B), and the effects of the knockdown of AM via siRNA were identified (Figure $2 \mathrm{~F}$ ). The negative control, FAM, was used to monitor and optimize transfection efficiency. Annexin V/PI staining demonstrated that AM knockdown promotes apoptosis in BGC-823 cells (Figure 3E). A colony formation assay demonstrated that gastric cancer tumor growth was significantly decreased after the BGC-823 cells were transfected with AM siRNA (Figure 3F, 3G). The MTT cell proliferation assay showed no statistical significance. The wound healing assay and trans-well migration assay indicated that cellular migration activity decreased in response to the AM knockdown (Figure 3A-3D). 


\section{AM regulates the AKT signaling pathway}

Our western blot analysis results showed P-AKT expression is reduced in response to reduced levels of $\mathrm{AM}$ in our knockdown assay, however, pronounced changes in P-PKA and P-JNK levels were not observed (Figure 4C, 4D). Furthermore, our results showed that AM-siRNA treatment might inhibit the Proteinkinase $\mathrm{B}$ (PKB, also known as Akt) signaling pathway and slightly suppress PKA activation. AM-siRNA activated the apoptosis mechanism. Our western blot results showed that $\mathrm{Bcl} 2$ expression was reduced, while cleaved-caspase 3 and Bax expression was up-regulated (Figure 4A, 4B).

\section{HIF-1 $\alpha$ regulates the expression of $A M$ and VEGFA in the early stages of hypoxia, whereas NDRG3 regulates the late stages}

AM, VEGFA, NDRG3, and HIF-1 $\alpha$ mRNA expression levels were measured under hypoxic conditions. Our qRT-PCR results showed the expression of AM, VEGFA, NDRG3, and HIF-1 $\alpha$ allincreased, though to different degrees, and at different times, in the gastric cancer cell lines. After $6 \mathrm{~h}$ of culture, the expression of $\mathrm{AM}$ peaked (Figure $5 \mathrm{C}$ ), whereas the expression of NDRG3 did not rise significantly until 24 $\mathrm{h}$ after exposure to hypoxic conditions (Figure 5D). Our results showed that HIF- $1 \alpha$ regulates the expression of the AM and VEGFA genes in the early stages of hypoxia, whereas NDRG3 regulates the later stages.

\section{AM does not have a role in the regulation of autophagy in BGC-823 cells}

Western blots were used to determine the changes in the LC3-II/I ratio and Beclin protein levels to evaluate autophagy. No significant changes in theLC3-II/I ratio or Beclin protein levels were observed (Figure 6B, 6C). Our confocal microscope tracer autophagosome formation results showed that the BGC-823 cells, transfected with AM-siRNA and pcDNA-AM, had no effect on the rate of autophagy.
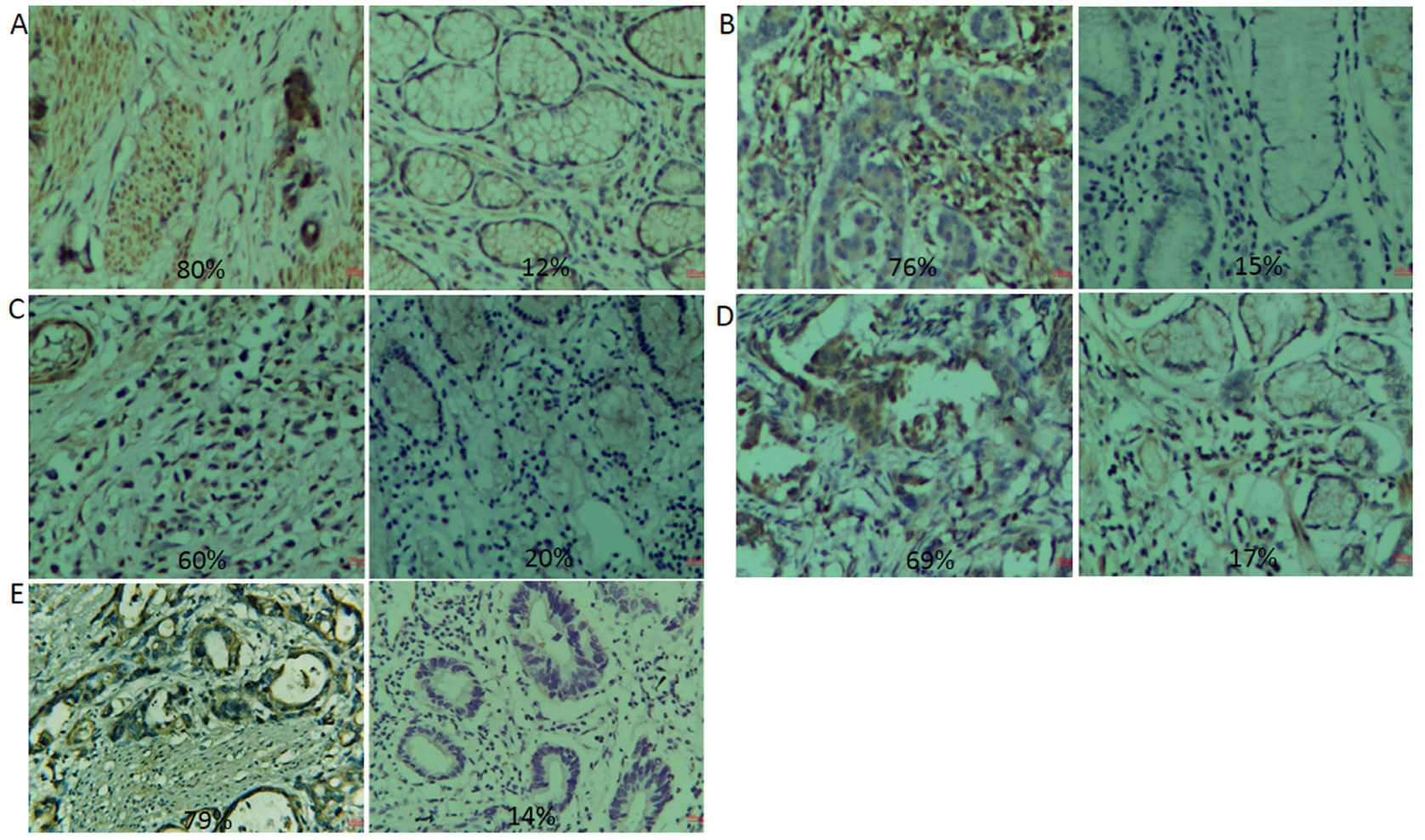

Figure 1: Immunohistochemical staining of tissue specimens. The intensity of AM and AM receptor staining in the gastric cancer tissue samples was scored as 0\% (negative), 25\% (weak), 50\% (moderate), 75\% (strong), or 100\% (strongest) as determined by a pathologist from ADICON CLINICAL LABORATORIES. (A) Staining showing the expression of AM (left, gastric cancer tissue; right, adjacent tissue). (B) Staining showing the expression of RAMP1 (left, gastric cancer tissue; right, adjacent tissue). (C) Staining showing the expression of RAMP2 (left, gastric cancer tissue; right, adjacent tissue). (D) Staining showing the expression of RAMP3 (left, gastric cancer tissue; right, adjacent tissue). (E) Staining showing the expression of CRLR(left, gastric cancer tissue; right, adjacent tissue). 


\section{DISCUSSION}

The expression of AM and AM receptors has been shown to be elevated in human lung, colon, ovary, breast, bone marrow, prostate, and cartilage cancer cell lines [26]. Furthermore, in melanomas, the expression levels of AM, CLR, RAMP2, and RAMP3 have been shown to be higher than those in the control tissues [27]. In this study, we found that the levels of the AM protein and its receptors CRLR, RAMP1, RAMP2, and RAMP3 were also significantly increased, as compared to the adjacent healthy gastric tissues. In colorectal carcinomas, a correlation between high AM mRNA expression and protein levels has also been demonstrated [28-30]. Furthermore, AM and RAMP mRNA levels have been shown to be higher in pancreatic adenocarcinoma tissues, skin carcinomas, and pheochromocytomas, as compared to normal pancreatic tissue [27, 31, 32]. However, our results are not consistent with those of the above-mentioned previous studies; therefore, further investigation is necessary.

Malignant cancer cells have been shown to have elevated growth signal levels, angiogenesis and metastasis, and to inhibit apoptosis [33, 34]. Our results show that BGC-823 cells transfected with AM siRNA have significantly decreased gastric cancer growth and cellular migration activity. Our flow cytometry results indicate that AM knockdown promotes apoptosis in gastric cells. Previous studies have reported similar results, showing RNA interference targeting of AM induces apoptosis and reduces growth in human bladder urothelial cell carcinomas [22], and that AM is a

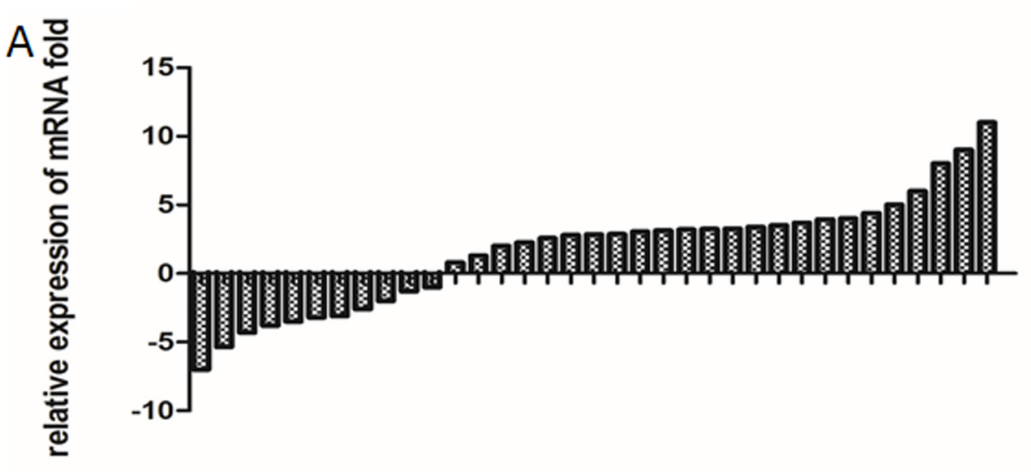

C MGC BGC-823 MKN-45 HGC SGC-790
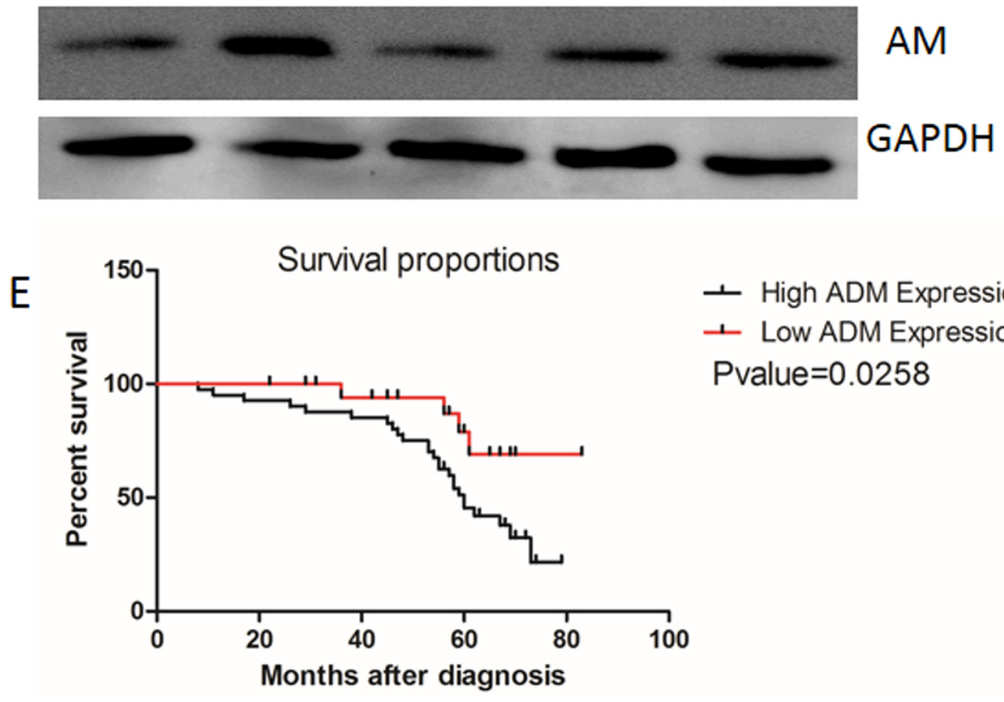
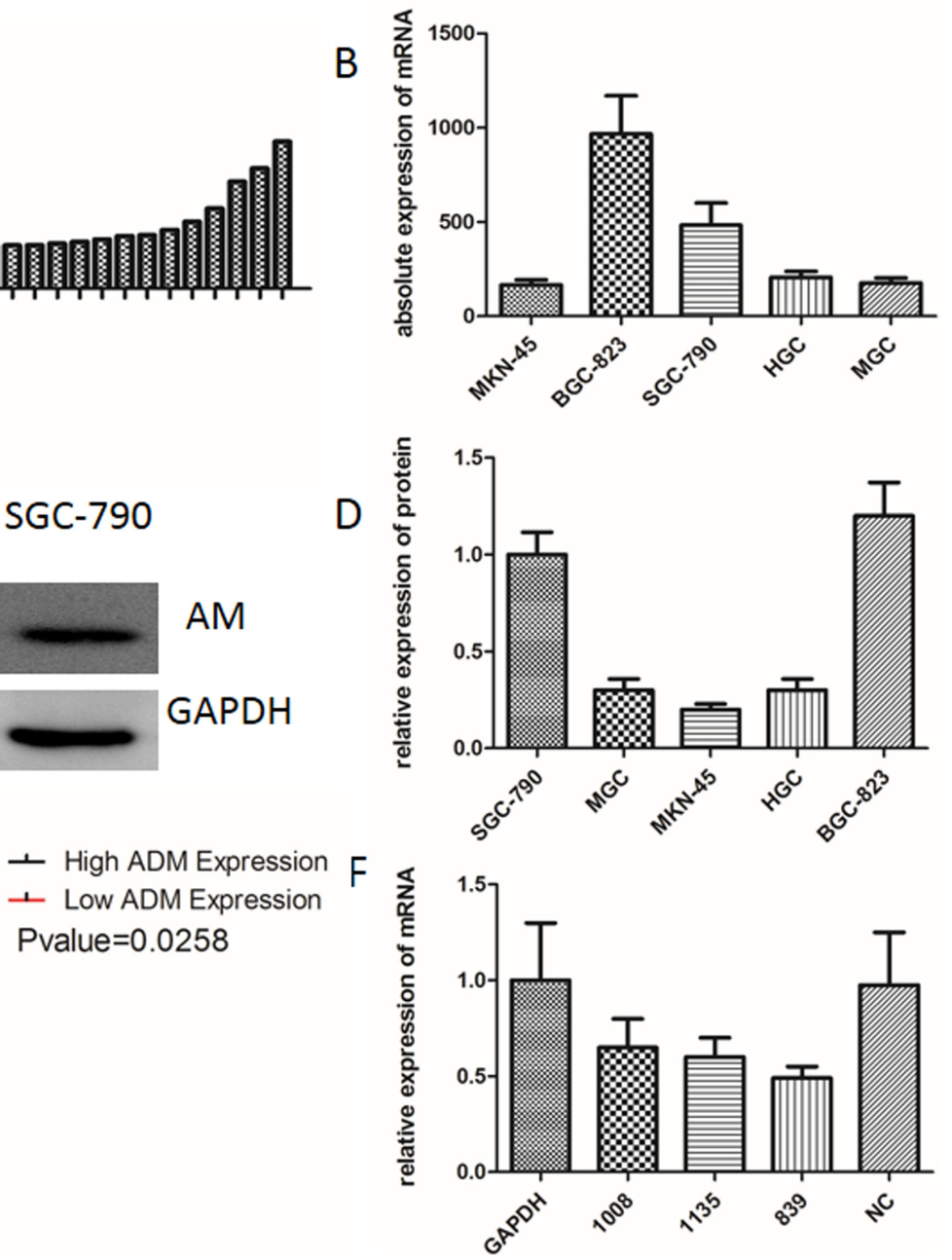

Figure 2: (A) qRT-PCR results showing the AM mRNA levels in 35 gastric cancer specimens. (B) Relative AM mRNA levels in the gastric cancer cell lines examined. (E) Survival analysis of the 60 clinical patients (P-value=0.0258). (C) Western blot showing the expression level of AM in the gastric cancer cell lines BGC-823, MKN-45, SGC-790, HGC, and MGC. (D) Gray-scale scanning histogram of the (C). (F) qRT-PCR AM mRNA levels in transfected BGC-823 cells. 
Table 1: Clinicopathological features and the expression of AM in gastric cancer patients

\begin{tabular}{|c|c|c|c|c|c|c|}
\hline \multirow{2}{*}{ Parameters } & \multirow{2}{*}{ Group } & \multicolumn{4}{|c|}{$\mathbf{A M}$} & \multirow{2}{*}{ P value } \\
\hline & & $0 \%-25 \%$ & $26 \%-74 \%$ & $75 \%-100 \%$ & Total & \\
\hline \multirow[t]{2}{*}{ Age (years) } & $\leq 60$ & 12 & 9 & 25 & 46 & 0.731 \\
\hline & $>60$ & 3 & 2 & 9 & 14 & \\
\hline \multirow[t]{2}{*}{ Gender } & Male & 10 & 8 & 28 & 46 & 0.495 \\
\hline & Female & 2 & 2 & 10 & 14 & \\
\hline \multirow[t]{2}{*}{ Tumor size } & $\mathrm{T} 1-\mathrm{T} 2$ & 5 & 5 & 6 & 16 & 0.008 \\
\hline & $\mathrm{T} 3-\mathrm{T} 4$ & 2 & 12 & 30 & 44 & \\
\hline \multirow[t]{2}{*}{ Tumor grade } & G1 & 12 & 5 & 6 & 23 & 0.012 \\
\hline & G2/G3 & 7 & 12 & 18 & 37 & \\
\hline \multirow[t]{2}{*}{ Distant metastasis } & Yes & 5 & 6 & 10 & 21 & 0.716 \\
\hline & No & 9 & 7 & 23 & 39 & \\
\hline \multirow[t]{2}{*}{ TNM stage } & I-II & 5 & 7 & 7 & 19 & 0.011 \\
\hline & III-IV & 3 & 8 & 30 & 41 & \\
\hline
\end{tabular}

The high expression samples (75\%-100\%) and low expression samples ( $0 \%-25 \%)$ were evaluated using chi-square test.
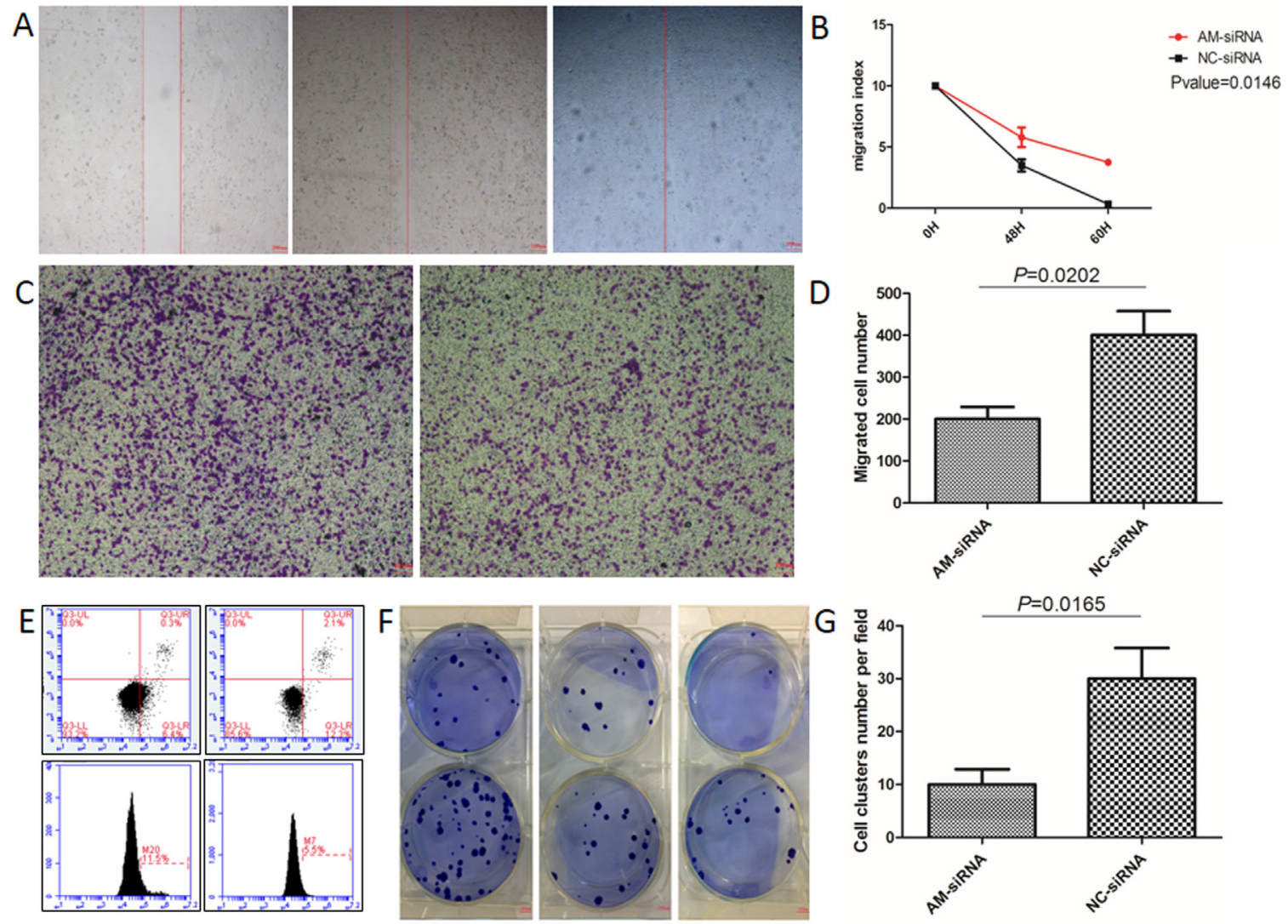

Figure 3: BGC-823 cells transfected with AM siRNA-839. (A) Wound healing assay (left, 0 h control group; middle, siRNA-839 $60 \mathrm{~h}$ group; right, siRNA-GAPDH 60 h). (B) Quantitative analysis of (A) (P-value=0.0146). (C) Trans-well migration assay (left, siRNAGAPDH experimental group; right, siRNA-839 control group). (D) Quantitative analysis of (C). The data represent the mean \pm SEM (P-value=0.0202). (E) Annexin V/PI staining (left, basic level of cell apoptosis; right, siRNA-839 cell apoptosis rate. (F) Colony forming assay (top, siRNA-839 experimental group; bottom, siRNA-GAPDH control group). (G) Quantitative analysis of (F). The data represent the mean \pm SEM (P-value $=0.0165)$. 


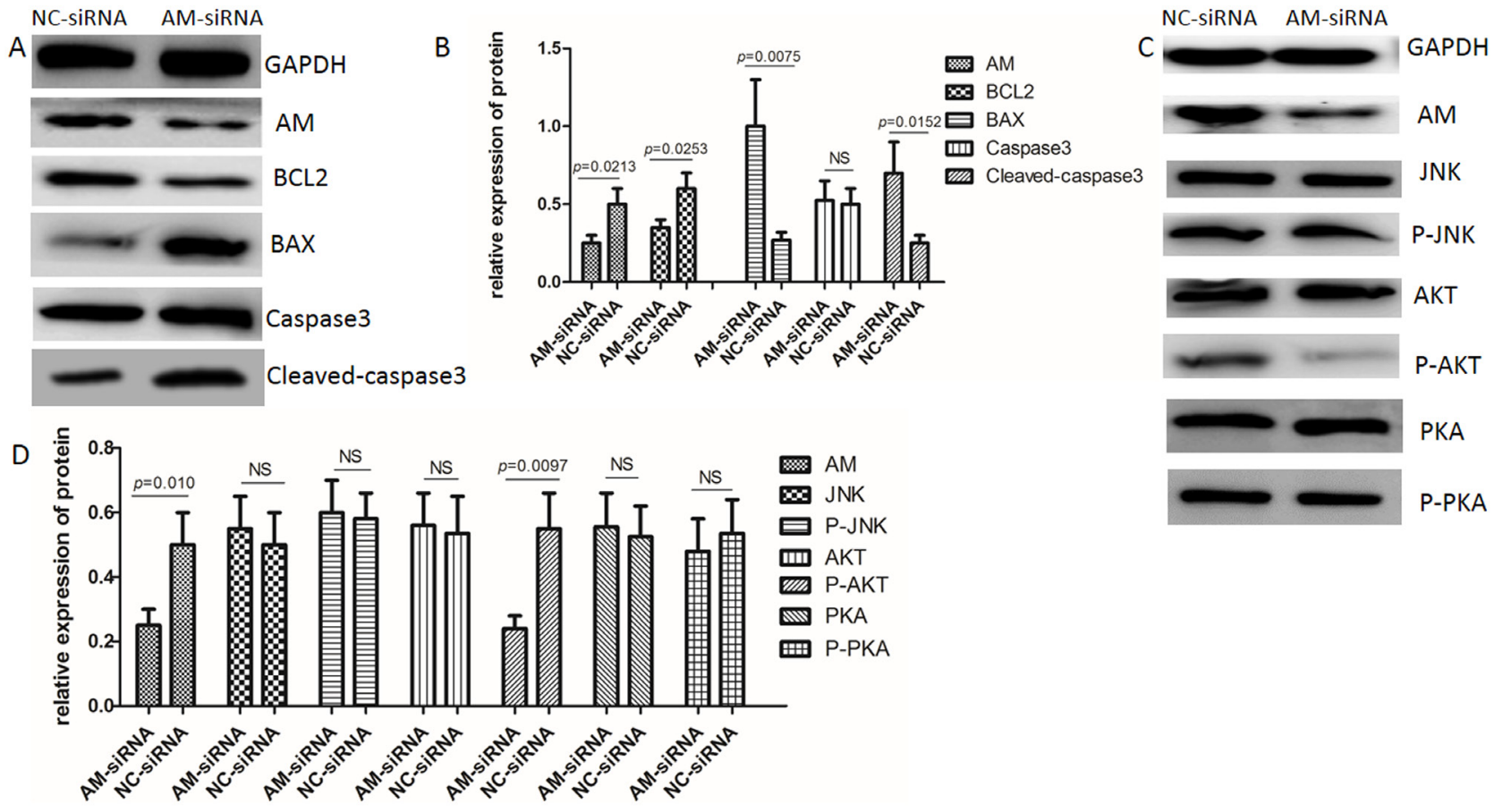

Figure 4: The AKT signaling pathway is down-regulated resulting in cell apoptosis. (A) Western blot showing that Bcl2 levels are reduced while Bax and cleaved-caspase 3 are elevated in response to AM knockdown. (B) Gray-scale scanning histogram of (A). The data represent the mean \pm SEM (P-value $=0.0213$; P-value $=0.0253$; P-value $=0.0075 ; \mathrm{P}$-value $=0.0152)$. (C) Western blot showing $\mathrm{P}$-AKT levels are reduced in response to AM knockdown. (D) Gray-scale scanning histogram of (C). The data represent the mean \pm SEM (P-value=0.010; P-value $=0.0097)$.

A

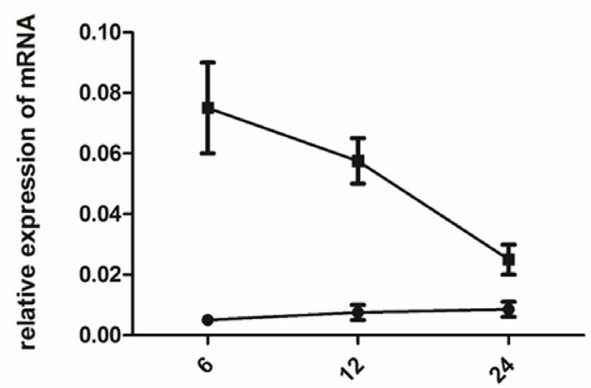

$\mathrm{C}$

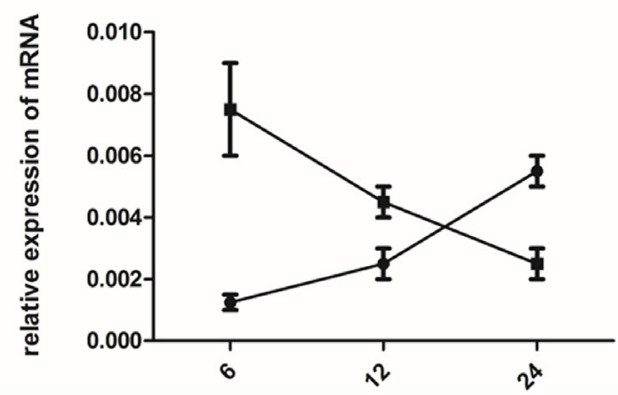

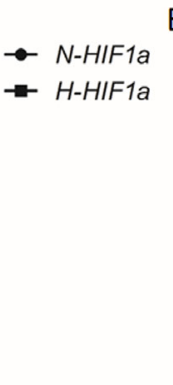

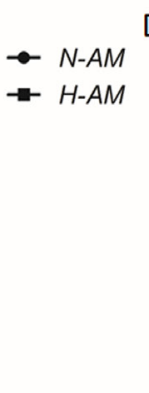

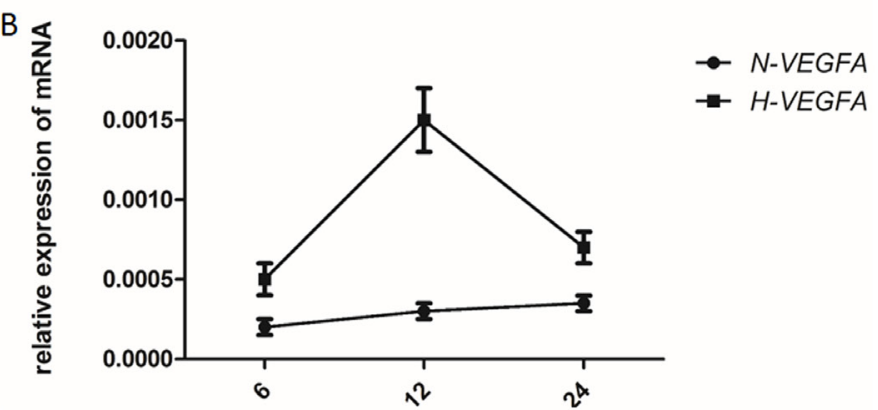

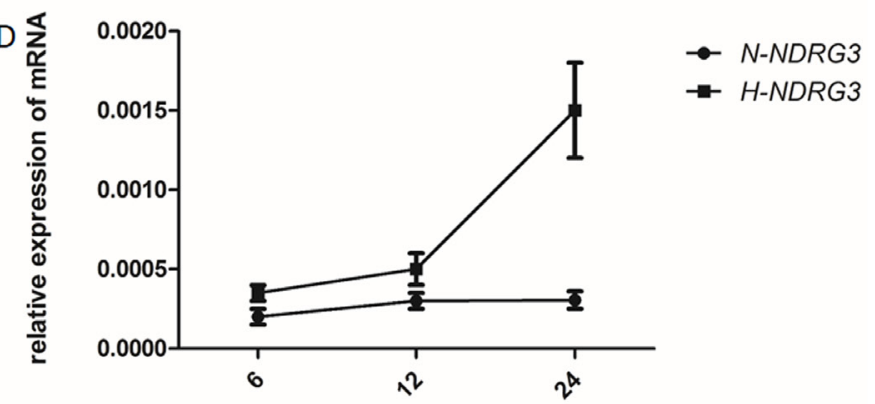

Figure 5: Induction of hypoxia in gastric cancer BGC-823 cells. (A) Relative mRNA levels of AM, VEGFA, NDRG3, and HIF$1 \alpha$ following hypoxia treatment. The control group was treated using normal culture conditions in parallel. Charts (A, B, C, and D) show HIF1a, VEGFA, AM, and NDRG3, respectively. Expression levels of each target mRNA are expressed relative to GAPDH levels. 
potential therapeutic target in the treatment of colorectal cancer [28]. Furthermore, several studies have shown that AM receptors are effective targets in the treatment of pancreatic cancer [35]. Our results suggest that RNA interference-mediated silencing of AM suppresses gastric tumor growth, and may represent a novel strategy for the treatment of gastric cancer.

When tumor cells are exposed to hypoxic conditions, HIF-1 $\alpha$ up-regulates several genes promoting the growth and survival of tumor cells [36, 37]. This response to hypoxia results in the accumulation of lactate [38], which enables the formation of the tumor microenvironment. Under hypoxic conditions, the expression of AM, HIF-1 $\alpha$, NDRG3, and VEGFA are significantly elevated in the human gastric cancer cell line BGC-823. Under similar conditions, human colorectal carcinoma cells have also been shown to display a time-dependent increase in AM mRNA and peptide expression [28]. Alternatively, the expression of AM and NDRG3 has been shown to not be time independent. AM is known to be involved in the early stage of the cellular mechanism of oxygen sensing, whereas NDRG3 is involved in the late phase [38]; moreover, AM is involved in the regulation of the tumor microenvironment. Therefore, AM may be involved in microvessel proliferation and partially in the release of hypoxia in solid tumors.

Autophagy is an evolutionary conserved catabolic process by which cells are degraded and recycled to maintain cellular homeostasis [23]. Several reports have found a connection between autophagy and apoptosis, and the regulation of starvation-induced autophagy by the phosphorylation of Bcl-2 [39, 40]. Furthermore, some studies have shown the regulation of autophagy is altered by the calcium signalosome in human diseases [23]. Other studies have demonstrated that AM can induce the mobilization of $\mathrm{Ca}^{2+}$ independent of cAMP levels [25]. In the present study, we used western blot analysis to detect changes in the LC3II/I ratio, alongside the Beclin protein, to evaluate autophagy. Tracer autophagy bodies were examined, using a confocal laser scanning microscope; however, no significant changes were found. Therefore, further research examining the relationship between AM and autophagy is required.

In conclusion, our results indicate that AM plays a significant role in the proliferation, migration, and angiogenesis of gastric cancer, and RNA interferencemediated knockdown of AM and AM receptors may provide a novel treatment strategy for gastric cancer and/or solid tumor.
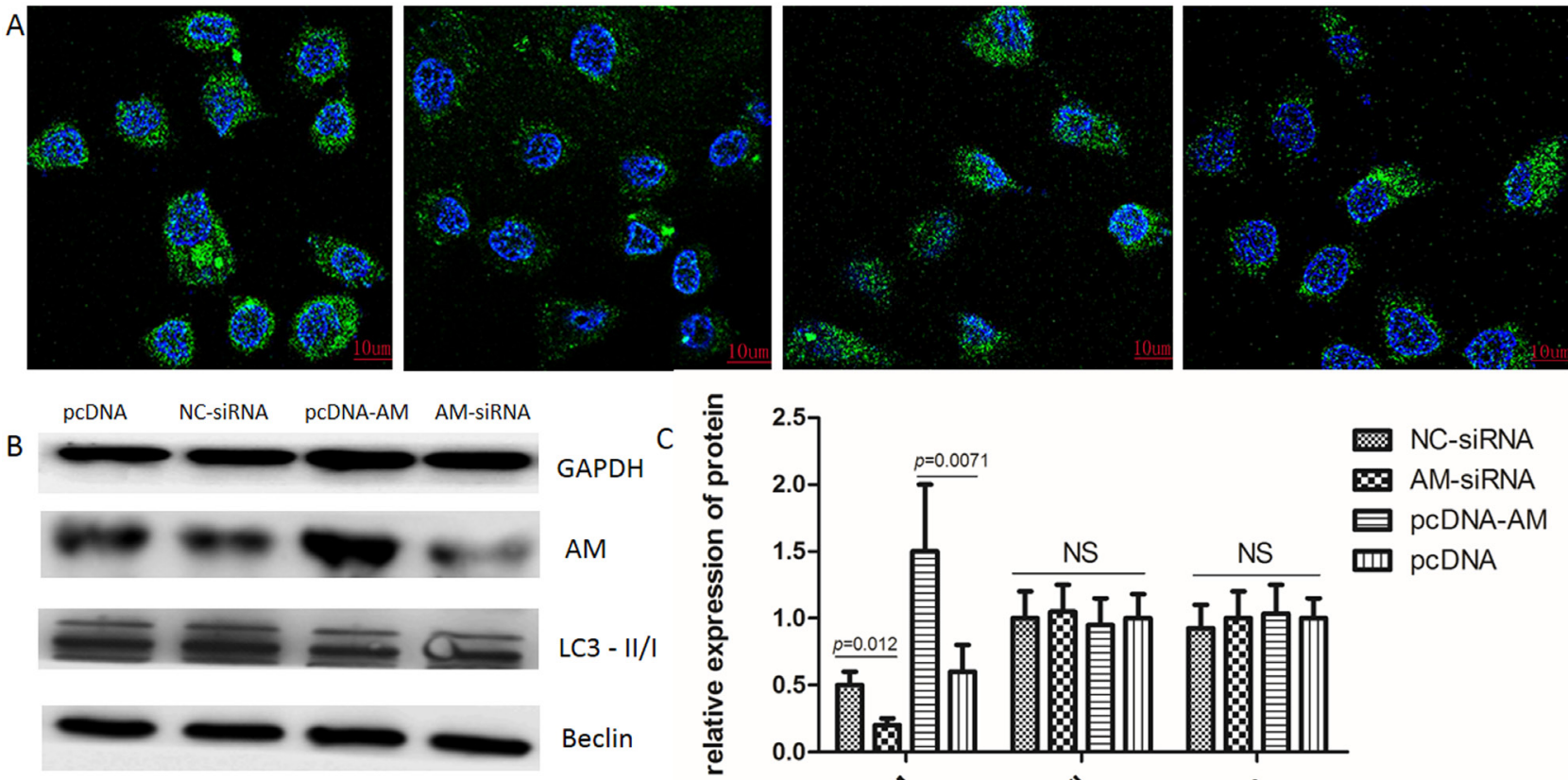

GAPDH

AM

LC3 $-11 / 1$

Beclin
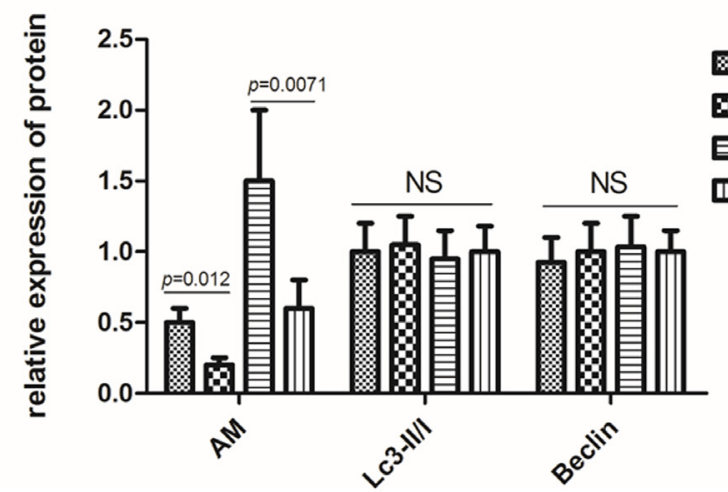

Figure 6: GFP-LC3 single fluorescent indicator autophagy. (A) Tracer auto-phagosome formation. The images show the results of transfection with pcDNA and pcDNA-GFP-LC3, NC-siRNA and pcDNA-GFP-LC3, pcDNA-AM and pcDNA-GFP-LC3, and siRNA-839 and pcDNA-GFP-LC3 vectors, respectively. (B) Western blots showing the LC3-II/I ratio and Beclin levels were not changed. (C) Gray-scale scanning histogram of (B). The data represent the mean \pm SEM (P-value=0.0120; P-value=0.0071). 


\section{MATERIALS AND METHODS}

\section{Tissue specimens and patient clinical information}

In total, 120 stomach tissue samples were collected and embedded in paraffin (FFPE) in accordance with the Ethics Committee of the School of Medicine (Jiangsu University) guidelines. Two samples were obtained from each of 60 patients diagnosed with adenocarcinoma: one cancerous tissue sample and one adjacent non-cancerous tissue sample. All tissue blocks were obtained from the Department of Pathology at the Affiliated Hospital of Jiangsu University between 2010 and 2015. None of the patients included in this study had received treatment (radiation therapy, chemotherapy, or immunotherapy) before surgical resection. The clinicopathological characteristics of the patients are presented in Table 1.

\section{Cell culture and reagents}

Human gastric cancer cell lines, including BGC823, MGC, SGC-790, HGC, and MKN-45 were purchased from the American Type Culture Collection in 2015. All cells were cultured in DMEM, supplemented with $10 \%$ fetal bovine serum, and were grown in a humidified atmosphere containing a $95 \%$ air, $5 \% \mathrm{CO} 2$ mixture at $37^{\circ} \mathrm{C}$. Anti-AM, anti-P-JNK, anti-JNK, anti-P-PKA, anti-PKA, and anti-LC3-II/I antibodies were obtained from Abcam Technology (Cambridge, MA). Anticleaved-caspase3, anti-caspase3, anti-P-AKT, anti-AKT, anti-Beclin, and anti-CRLR antibodies were obtained from Santa Cruz Biotechnology (Santa Cruz, CA). AntiGAPDH, anti-Bax, anti-Bcl2, anti-RAMP1, anti-RAMP2, and anti-RAMP3 antibodies were obtained from Cell Signaling Technology (Beverly, MA).

\section{Immunohistochemical staining}

The cell lines were treated with primary antibodies against AM (1:200), CRLR (1:100), RAMP1 (1:100), $\operatorname{RAMP} 2(1: 100)$, and RAMP3 $(1: 100)$ at $4{ }^{\circ} \mathrm{C}$ overnight. A 1:500 dilution of the corresponding peroxidase-conjugated IgG antibody was incubated with a streptavidin-peroxidase complex, using the Vectastain Elite $\mathrm{ABC}$ Universal kit (Vector Laboratories, Burlingame, CA) for $30 \mathrm{~min}$ at room temperature, and developed using a 3,3'-diaminobenzidine substrate. The specimens were counterstained with Gill's hematoxylin, and dehydrated using ethanol before being fixed with xylene and subsequently mounted. The AM, CRLR, RAMP1, RAMP2, and RAMP3 stained cells were counted, in 5 randomly selected fields, on each slide at $400 \times$ magnification. The intensity of AM and AM receptor staining in the gastric cancer tissue samples was scored as $0 \%$ (negative), $25 \%$ (weak), 50\% (moderate), $75 \%$ (strong), or $100 \%$ (strongest), as determined by a pathologist from ADICON CLINICAL LABORATORIES.
Gene silencing in the BGC-823 cell line using AM-siRNA

BGC-823 cells were seeded to 6-well plates $\left(2.5 \times 10^{5} \mathrm{cells} / \mathrm{well}\right)$ and allowed to adhere for $24 \mathrm{~h}$ before transfection. Using Lipofectamine 2000 (Invitrogen, Groningen, Netherlands), the cells were transfected with siRNAs directed against human AM (AM-siRNA; GenePharma, Shanghai, China) or non-targeted control siRNAs (NC-siRNA; GenePharma). FAM (GenePharma) was used as a negative control to monitor and optimize transfection efficiency.

\section{Induction of hypoxia in gastric cancer cells}

BGC-823 cells were seeded to 6-well plates, at a density of $3 \times 10^{5}$ cells/well, to facilitate an exponential growth rate. The assay was then divided into six treatments: $6 \mathrm{~h}$ hypoxia, $6 \mathrm{~h}$ non-hypoxia, $12 \mathrm{~h}$ hypoxia, $12 \mathrm{~h}$ non-hypoxia, $24 \mathrm{~h}$ hypoxia, and $24 \mathrm{~h}$ non-hypoxia. Each treatment was replicated three separate wells. Each hypoxia treatment was exposed to $1 \% \mathrm{O}_{2}, 5 \% \mathrm{CO}_{2}$, and $94 \% \mathrm{~N}_{2}$, at $37^{\circ} \mathrm{C}$, for the designated period, and the non-hypoxia treatments were placed in a humidified atmosphere with a $95 \%$ air, $5 \% \mathrm{CO}_{2}$ mixture at $37^{\circ} \mathrm{C}$. Twenty-four hours after treatment, the cells were digested with trypsin, and total RNA and protein were extracted for analysis.

\section{Immunoblot analysis}

Cell samples were washed in cold PBS, lysed for 20 min on ice with lysis buffer, and centrifuged at $14,000 \mathrm{~g}$ for $10 \mathrm{~min}$ at $4{ }^{\circ} \mathrm{C}$. The supernatant was collected and the protein concentration was determined using the Bradford assay (Bio-Rad Laboratories, Hercules, CA, USA). Total protein was separated on a $10 \%$ SDS-polyacrylamide gel and transferred to a PVDF membrane (Bio-Rad). The membranes were blocked with 5\% skimmed milk for $1 \mathrm{~h}$ and incubated overnight at $4^{\circ} \mathrm{C}$ with the following primary antibodies: anti-AM, anti-P-JNK, anti-JNK, anti-P-PKA, anti-PKA, anti-Bax, anti-Bcl2 anti-caspase3, anti-Beclin, anti-cleaved-caspase3, and anti-LC3-II/I diluted 1:1,000, and anti-P-AKT, anti-AKT, and anti-GAPDH diluted 1:2,000. The membranes were then incubated with a secondary antibody for $1.5 \mathrm{~h}$ at room temperature. Bound antibodies were visualized using a chemiluminescent substrate (ECL, Amersham, Arlington Heights, IL)

\section{RNA extraction and real-time quantitative reverse transcription-PCR (qRT-PCR)}

Total RNA was extracted from BGC-823 cells using the RNA iso Plus Kit (Takara, Dalian, China). Between $10 \mathrm{pg}$ and $1 \mu \mathrm{g}$ total RNA was used for firststrand DNA synthesis using the PrimeScript RT Reagent Kit (Takara), and qRT-PCR was performed 
using the Top Green qPCR SuperMix and Passive Reference Dye (Takara). The following primers were used for amplification: AM, forward primer (5'-CACTTCGGGCTTCTCACTGC-3') and reverse primer (5'-ACATCAGGGCGACGGAAAC-3') TM value: $60^{\circ} \mathrm{C}$; VEGFA, forward primer (5'-AGGCCAGCA CATAGGAGAGA- $3^{\prime}$ ) and reverse primer (5'-TTTC TTGCGCTTTCGTTTTT-3') TM value: $60^{\circ} \mathrm{C}$; HIF-1 $\alpha$, forward primer (5'-GAAAGCGCAAGTCCTCAAAG-3') and reverse primer (5'-TGGGTAGGAGATGGAGA TGC-3') TM value: $60^{\circ} \mathrm{C}$; NDRG3, forward primer (5'-GACAAGCGCGCAGTCTCAAG-3') and reverse primer (5'-TGAGTAGGAGTGCGAATCCGC-3') TM value: $58^{\circ} \mathrm{C}$; and $\mathrm{GAPDH}$, forward primer $\left(5^{\prime}-\mathrm{TTGG}\right.$ TATCGTGGAAGGACTCA-3') and reverse primer (5'-CAGTAGAGGCAGGGATGATGT-3') TM value: $60^{\circ} \mathrm{C}$. The annealing temperature was optimized by gradient PCR for each primer pair. The relative expression of each target mRNA relative to GAPDH mRNA was calculated using the $\Delta \Delta \mathrm{Ct}$ method.

\section{Flow cytometry}

BGC-823 cells were transfected with AM siRNA after $48 \mathrm{~h}$ of cell growth and flow cytometry was used to detect apoptosis. The cells were stained with Annexin V-FITC and PI using an Apoptosis Detection Kit (SigmaAldrich, St. Louis, MO) according to the manufacturer's instructions. BGC-823 cells transfected with FAM siRNA were used as the negative control group. The cells were counted with a FACS Calibur flow cytometer.

\section{GFP-LC3 single fluorescent autophagy indicator system}

The pcDNA-GFP-LC3 single fluorescent autophagy indicator system was constructed as follows. AM-siRNA and pcDNA-GFP-LC3 vectors were used to transfect BGC-823 cells and transfected pcDNA-AM and pcDNAGFP-LC3 vectors were used as controls. After $48 \mathrm{~h}$ of culture, western blots were used to detect LC3-II/I ratio changes in the Beclin protein to evaluate autophagy. The cells were counter-stained with DAPI 40727ES10 (Beyotime Institute of Biotechnology) for $20 \mathrm{~min}$. Stained specimens were imaged using a confocal laser scanning microscope (Olympus).

\section{Statistical analysis}

The in vitro experimental data depicted represent at least three independent experiments. Data are expressed as the means of the three or more independent experiments' 6 standard error of the mean (SEM). The high expressing samples (AM: $75 \%$ to $100 \%$ ) and low expressing samples (AM: $0 \%$ to $25 \%$ ) were evaluated using the chi-square test. Significant differences between controls and treated samples were evaluated using one-way analysis of variance (ANOVA) with SPSS software. The results were considered to be statistically significant if the $p$ value was less than 0.05. Data were compared using GraphPad Prism 5 software.

\section{ACKNOWLEDGMENTS}

This work was supported by the National Natural Science Foundation of China (grant nos. 81301396 and 81271795), the Natural Science Foundation of Jiangsu Province, China (grant nos. BK20161345 and BK20130542), and the Key R and D programs-social development of Zhenjiang, Jiangsu, China (grant no. SH2015080).

\section{CONFLICTS OF INTEREST}

The researchers report no conflicts of interest.

\section{REFERENCES}

1. Webpage, Dictionary Definition of Adrenomedullin. http:// encyclopedia.thefreedictionary.com/Adrenomedullin\#cite_ note-1.

2. Chan BA, Jang RW, Wong RK, Swallow CJ, Darling GE, Elimova E. Improving outcomes in resectable gastric cancer: a review of current and future strategies. Oncology (Williston Park). 2016; 30:635-45.

3. Ferlay J, Soerjomataram I, Dikshit R, Eser S, Mathers C, Rebelo M, Parkin DM, Forman D, Bray F. Cancer incidence and mortality worldwide: sources, methods and major patterns in GLOBOCAN 2012. Int J Cancer. 2015; 136:E359-86.

4. Fitzmaurice C, Dicker D, Pain A, Hamavid H, MoradiLakeh M, MacIntyre MF, Allen C, Hansen G, Woodbrook R, Wolfe C, Hamadeh RR, Moore A, Werdecker A; Global Burden of Disease Cancer Collaboration. The Global Burden of Cancer 2013. JAMA Oncol. 2015; 1:505-27.

5. Anderson LA, Tavilla A, Brenner H, Luttmann S, Navarro C, Gavin AT, Holleczek B, Johnston BT, Cook MB, Bannon F, Sant M, Hackl M, Zielonke N; EUROCARE-5 Working Group. Survival for oesophageal, stomach and small intestine cancers in Europe 1999-2007: results from EUROCARE-5. Eur J Cancer. 2015; 51:2144-57.

6. Spolverato G, Ejaz A, Kim Y, Squires MH, Poultsides GA, Fields RC, Schmidt C, Weber SM, Votanopoulos K, Maithel SK, Pawlik TM. Rates and patterns of recurrence after curative intent resection for gastric cancer: a United States multi-institutional analysis. J Am Coll Surg. 2014; 219:664-75.

7. Wang Y, Huang CM, Wang JB, Zheng CH, Li P, Xie JW, Lin JX, Lu J. Survival and surgical outcomes of cardiac 
cancer of the remnant stomach in comparison with primary cardiac cancer. World J Surg Oncol. 2014; 12:21.

8. Le A, Berger D, Lau M, El-Serag HB. Secular trends in the use, quality, and outcomes of gastrectomy for noncardia gastric cancer in the United States. Ann Surg Oncol. 2007; 14:2519-27.

9. Lau M, Le A, El-Serag HB. Noncardia gastric adenocarcinoma remains an important and deadly cancer in the United States: secular trends in incidence and survival. Am J Gastroenterol. 2006; 101:2485-92.

10. Dai X, Ma W, He XJ, Jha RK. Elevated expression of adrenomedullin is correlated with prognosis and disease severity in osteosarcoma. Med Oncol. 2013; 30:347.

11. Aggarwal G, Ramachandran V, Javeed N, Arumugam T, Dutta S, Klee GG, Klee EW, Smyrk TC, Bamlet W, Han JJ, Rumie Vittar NB, de Andrade M, Mukhopadhyay D, et al. Adrenomedullin is up-regulated in patients with pancreatic cancer and causes insulin resistance in $\beta$ cells and mice. Gastroenterology. 2012; 143:1510-17.e1.

12. Hummel TR, Jessen WJ, Miller SJ, Kluwe L, Mautner VF, Wallace MR, Lázaro C, Page GP, Worley PF, Aronow BJ, Schorry EK, Ratner N. Gene expression analysis identifies potential biomarkers of neurofibromatosis type 1 including adrenomedullin. Clin Cancer Res. 2010; 16:5048-57.

13. Martínez-Herrero S, Larráyoz IM, Ochoa-Callejero L, García-Sanmartín J, Martínez A. Adrenomedullin as a growth and cell fate regulatory factor for adult neural stem cells. Stem Cells Int. 2012; 2012:804717.

14. Allaker RP, Kapas S. Adrenomedullin expression by gastric epithelial cells in response to infection. Clin Diagn Lab Immunol. 2003; 10:546-51.

15. Hirsch AB, McCuen RW, Arimura A, Schubert ML. Adrenomedullin stimulates somatostatin and thus inhibits histamine and acid secretion in the fundus of the stomach. Regul Pept. 2003; 110:189-95.

16. Evans JJ, Chitcholtan K, Dann JM, Guilford P, Harris G, Lewis LK, Nagase J, Welkamp AA, Zwerus R, Sykes PH. Adrenomedullin interacts with VEGF in endometrial cancer and has varied modulation in tumours of different grades. Gynecol Oncol. 2012; 125:214-19.

17. Deville JL, Bartoli C, Berenguer C, Fernandez-Sauze S, Kaafarani I, Delfino C, Fina F, Salas S, Muracciole X, Mancini J, Lechevallier E, Martin PM, Figarella-Branger D, et al. Expression and role of adrenomedullin in renal tumors and value of its mRNA levels as prognostic factor in clearcell renal carcinoma. Int J Cancer. 2009; 125:2307-15.

18. Nishimatsu H, Suzuki E, Nagata D, Moriyama N, Satonaka H, Walsh K, Sata M, Kangawa K, Matsuo H, Goto A, Kitamura T, Hirata Y. Adrenomedullin induces endotheliumdependent vasorelaxation via the phosphatidylinositol 3-kinase/Akt-dependent pathway in rat aorta. Circ Res. 2001; 89:63-70.

19. Okumura H, Nagaya N, Itoh T, Okano I, Hino J, Mori $\mathrm{K}$, Tsukamoto Y, Ishibashi-Ueda H, Miwa S, Tambara K, Toyokuni S, Yutani C, Kangawa K. Adrenomedullin infusion attenuates myocardial ischemia/reperfusion injury through the phosphatidylinositol 3-kinase/Akt-dependent pathway. Circulation. 2004; 109:242-48.

20. Fritz-Six KL, Dunworth WP, Li M, Caron KM. Adrenomedullin signaling is necessary for murine lymphatic vascular development. J Clin Invest. 2008; 118:40-50.

21. Oehler MK, Norbury C, Hague S, Rees MC, Bicknell R. Adrenomedullin inhibits hypoxic cell death by upregulation of Bcl-2 in endometrial cancer cells: a possible promotion mechanism for tumour growth. Oncogene. 2001; 20:2937-45.

22. Liu AG, Zhang XZ, Li FB, Zhao YL, Guo YC, Yang RM. RNA interference targeting adrenomedullin induces apoptosis and reduces the growth of human bladder urothelial cell carcinoma. Med Oncol. 2013; 30:616.

23. Filippi-Chiela EC, Viegas MS, Thomé MP, Buffon A, Wink MR, Lenz G. Modulation of autophagy by calcium signalosome in human disease. Mol Pharmacol. 2016; 90:371-84.

24. Moon JY, Cho SK. Nobiletin induces protective autophagy accompanied by ER-stress mediated apoptosis in human gastric cancer SNU-16 cells. Molecules. 2016; 21:21.

25. Larráyoz IM, Martínez-Herrero S, García-Sanmartín J, Ochoa-Callejero L, Martínez A. Adrenomedullin and tumour microenvironment. J Transl Med. 2014; 12:339.

26. Miller MJ, Martínez A, Unsworth EJ, Thiele CJ, Moody TW, Elsasser T, Cuttitta F. Adrenomedullin expression in human tumor cell lines. Its potential role as an autocrine growth factor. J Biol Chem. 1996; 271:23345-51.

27. Chen P, Huang Y, Bong R, Ding Y, Song N, Wang X, Song X, Luo Y. Tumor-associated macrophages promote angiogenesis and melanoma growth via adrenomedullin in a paracrine and autocrine manner. Clin Cancer Res. 2011; 17:7230-39.

28. Wang L, Gala M, Yamamoto M, Pino MS, Kikuchi H, Shue DS, Shirasawa S, Austin TR, Lynch MP, Rueda BR, Zukerberg LR, Chung DC. Adrenomedullin is a therapeutic target in colorectal cancer. Int J Cancer. 2014; 134:2041-50.

29. Nouguerède E, Berenguer C, Garcia S, Bennani B, Delfino C, Nanni I, Dahan L, Gasmi M, Seitz JF, Martin PM, Ouafik L. Expression of adrenomedullin in human colorectal tumors and its role in cell growth and invasion in vitro and in xenograft growth in vivo. Cancer Med. 2013; 2:196-207.

30. Uemura M, Yamamoto H, Takemasa I, Mimori K, Mizushima T, Ikeda M, Sekimoto M, Doki Y, Mori M. Hypoxia-inducible adrenomedullin in colorectal cancer. Anticancer Res. 2011; 31:507-14.

31. Keleg S, Kayed H, Jiang X, Penzel R, Giese T, Büchler MW, Friess H, Kleeff J. Adrenomedullin is induced by hypoxia and enhances pancreatic cancer cell invasion. Int J Cancer. 2007; 121:21-32.

32. Thouënnon E, Pierre A, Tanguy Y, Guillemot J, Manecka DL, Guérin M, Ouafik L, Muresan M, Klein M, Bertherat J, Lefebvre H, Plouin PF, Yon L, Anouar Y. Expression of 
trophic amidated peptides and their receptors in benign and malignant pheochromocytomas: high expression of adrenomedullin RDC1 receptor and implication in tumoral cell survival. Endocr Relat Cancer. 2010; 17:637-51.

33. Cairns RA, Harris IS, Mak TW. Regulation of cancer cell metabolism. Nat Rev Cancer. 2011; 11:85-95.

34. Wouters BG, Koritzinsky M. Hypoxia signalling through $\mathrm{mTOR}$ and the unfolded protein response in cancer. Nat Rev Cancer. 2008; 8:851-64.

35. Ramachandran V, Arumugam T, Langley R, Hwang RF, Vivas-Mejia P, Sood AK, Lopez-Berestein G, Logsdon CD. The ADMR receptor mediates the effects of adrenomedullin on pancreatic cancer cells and on cells of the tumor microenvironment. PLoS One. 2009; 4:e7502.
36. Zudaire E, Martínez A, Cuttitta F. Adrenomedullin and cancer. Regul Pept. 2003; 112:175-83.

37. Wenger RH, Gassmann M. Oxygen(es) and the hypoxiainducible factor-1. Biol Chem. 1997; 378:609-16.

38. Lee DC, Sohn HA, Park ZY, Oh S, Kang YK, Lee KM, Kang M, Jang YJ, Yang SJ, Hong YK, Noh H, Kim JA, Kim DJ, et al. A lactate-induced response to hypoxia. Cell. $2015 ; 161: 595-609$.

39. Wei Y, Sinha S, Levine B. Dual role of JNK1-mediated phosphorylation of Bcl-2 in autophagy and apoptosis regulation. Autophagy. 2008; 4:949-51.

40. Wei Y, Pattingre S, Sinha S, Bassik M, Levine B. JNK1mediated phosphorylation of Bcl-2 regulates starvationinduced autophagy. Mol Cell. 2008; 30:678-88. 